\title{
Rapid changes in encrusting marine assemblages exposed to anthropogenic point-source pollution: a 'Beyond BACI' approach
}

\author{
D. E. Roberts ${ }^{1,3, *}$ A. Smith $^{2}$, P. Ajani ${ }^{1}$, A. R. Davis ${ }^{3}$ \\ ${ }^{1}$ Water Studies Section, Environment Protection Authority, Locked Bag 1502, Bankstown, New South Wales 2200, Australia \\ ${ }^{2}$ NSW Fisheries, Locked Bag 9, Pyrmont, New South Wales 2009, Australia \\ ${ }^{3}$ Department of Biological Sciences, University of Wollongong, Wollongong, New South Wales 2522, Australia
}

\begin{abstract}
Cover of and the number of species in encrusting macrobenthic assemblages inhabiting temperate rocky reefs in the vicinity of an ocean outfall changed rapidly following the discharge of secondary treated sewage effluent. Within 3 mo of the commissioning of the outfall, significant reductions in the cover of crustose and foliose algae were apparent when this outfall area was compared to 2 reference locations. The cover of several species of sponge, including Cymbastela concentrica, Geodinella sp. and Spongia sp., also underwent marked declines coincident with the commissioning of the outfall. Only 1 category of cover increased significantly at the outfall; this was a nondescript matrix comprising silt and microorganisms, which doubled its representation to almost $60 \%$. We did not detect significant declines in the cover and number of species of sponges or total fauna, however. A 'Beyond $\mathrm{BACl}^{\prime}$ experimental design was used to determine the environmental impact because of the great spatial and temporal variability in these shallow water $(-20 \mathrm{~m})$ encrusting communities. Photographic samples were taken in 3 periods, the first pre-commissioning and the other 2 post-commissioning. Multivariate analyses revealed marked shifts in the structure of the assemblage at the outfall relative to the reference locations; these shifts were clearly depicted by a non-metric multi-dimensional scaling (nMDS) plot. A SIMPER analysis confirmed that the overall composition of the community at the outfall changed from one in which algae and sponges were well represented to an assemblage dominated by silt and ascidians.
\end{abstract}

KEY WORDS: Sewage $\cdot$ Hard substratum - Macrobenthic $\cdot$ Subtidal $\cdot$ Sponges $\cdot$ Ascidians

\section{INTRODUCTION}

The spatial and temporal variation inherent in natural systems can make the detection of human impacts extremely difficult. This subject has drawn considerable attention in the study of marine systems and has been the subject of considerable discussion (Clarke \& Green 1988, Underwood \& Peterson 1988, Underwood 1992, Warwick \& Clarke 1993). The development of the before after, control impact (BACI) design (Green

\footnotetext{
-Address for reprint requests: D. E. Roberts, Marine and Estuarine Ecologist, Wyong Shire Council, PO Box 20, Wyong, New South Wales 2259, Australia

E-mail: dannio@bigpond.com.au
}

1979) and more recently the 'Beyond $\mathrm{BACI}^{\prime}$ design (Underwood 1991, 1992, 1993, 1994) has led to significant advances in the detection of impacts associated with anthropogenic disturbance. The Beyond BACI approach clearly acknowledges the importance of spatial and temporal sampling designs that ensure unconfounded detection of anthropogenic disturbance.

In coastal regions around the world, it has been convenient to discharge sewage effluent into the marine environment. In many instances, sewage is discharged onto subtidal rocky reefs exposed to high levels of water movement to ensure dilution. Sessile encrusting assemblages, including sponges and ascidians, often dominate the rock surfaces under these circumstances and because they are fixed to the substratum have a 
high probability of responding to the effects of sewage (Warwick 1993).

Temperate subtidal encrusting assemblages living on natural substrata are reputedly temporally stable (Ayling 1983) and those living on artificial substrata may be quite stable at medium scales, although highly dynamic at small scales (Kay \& Butler 1983, Butler \& Connolly 1996). Recent studies on assemblages living on natural substrata indicate that they are much more dynamic, particularly in shallow water (Kennelly \& Underwood 1992, Roberts \& Davis 1996), than previously thought and therefore the response of the assemblage to sewage-induced disturbance may be very rapid.

Many studies into the effects of sewage on subtidal rocky reef assemblages have been done after the potential disturbance has already occurred. These 'post hoc' studies abound (Littler \& Murray 1975, Lopez Gappa et al. 1990, Muricy 1991, Smith \& Simpson 1992, 1993, Smith 1994, Chapman et al. 1995, Roberts 1996); however, their numbers are insignificant when compared with the unpublished literature examining patterns associated with sewage. If we ignore that inappropriate design and/or logic (for example only 1 control) confounded many early studies, they are still generally inadequate, because predisturbance data was not collected. In practice, predisturbance data may be difficult (or impossible) to collect (see Roberts 1996) and the subsequent utility of monitoring programs that cannot, or do not, incorporate pre-impact data and appropriate controls is limited. Moreover, there is always the potential that any monitoring program will merely measure pre-existing differences between locations.

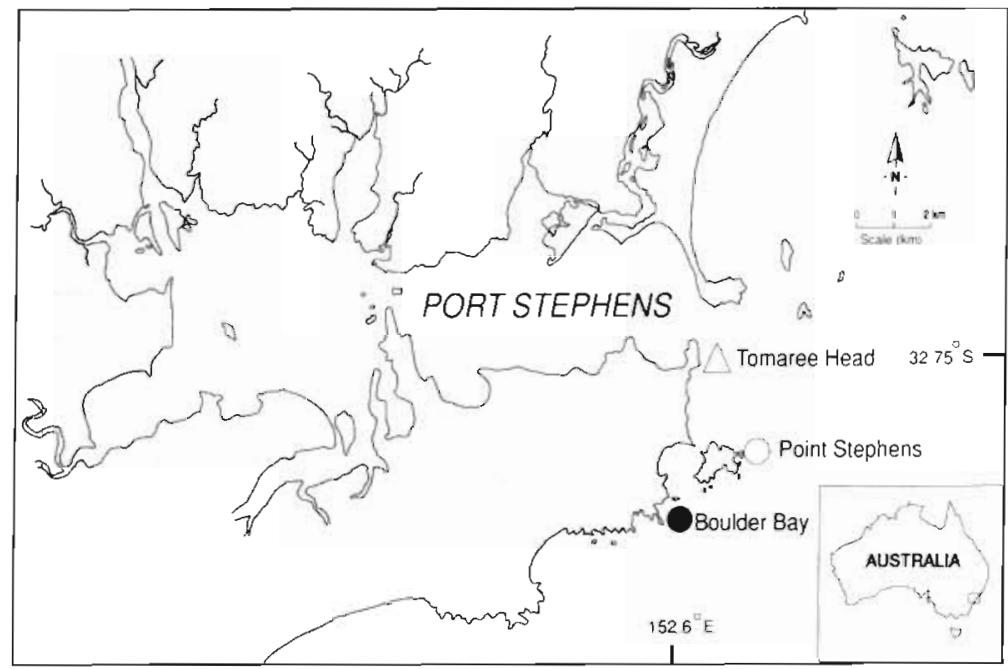

Fig. 1. Location of the Boulder Bay outfall and the controls at Point Stephens and Tomaree Head, New South Wales, Australia
In November 1993, the nearshore ocean outfall at Boulder Bay, New South Wales, Australia, began discharging approximately $3 \mathrm{Ml} \mathrm{d}^{-1}$ of secondary treated sewage effuent from 2 diffuser heads into subtidal rocky reef habitat at a depth of $20 \mathrm{~m}$. Here we document the effects of sewage discharge on sessile macrobenthic assemblages using both (1) a multivariate approach (Clarke \& Warwick 1994) and (2) a univariate asymmetrical analysis incorporating a Beyond BACI experimental design (Underwood 1994).

\section{METHODS}

Study locations and sampling design. To study the effects of sewage from the Boulder Bay outfall, assemblages were sampled at the outfall location (Boulder Bay-exposed to effluent) and at 2 control or reference locations (Point Stephens and Tomaree Head-no effluent) (Fig. 1). In general, the 3 locations were situated on rocky reef to a depth of approximately $20 \mathrm{~m}$ and the benthic community was dominated by erect sponges. Underwood et al. (1991) and Roberts \& Davis (1996) have described similar subtidal habitat for coastal waters in New South Wales.

The outfall location was situated within a $100 \mathrm{~m}$ radius of the diffusers and the assemblages were sampled using a diver-operated camera rig that supported a $35 \mathrm{~mm}$ Sea \& Sea Motor Marine-2 underwater camera and strobe. Investigations of the inshore and offshore circulation patterns around the outfall area were done to identify potential sewage plume movements from the outfall and to assess the suitability of controls. It was concluded from these investigations that the closest control location at Point Stephens (see Fig. 1) was independent of the effects of sewage (Lee \& Wallace 1993). It is also worth noting that there were no suitable accessible reference locations south of the outfall, i.e. subtidal rocky reef at 18 to $20 \mathrm{~m}$ depth

The assemblages at each location were sampled a total of 12 times over an 18 mo period from June 1993 to February 1995. The temporal design incorporated 4 random times within each of 3 periods, 1 before and 2 after the discharge of sewage. Because the temporal design was unbalanced, separate balanced analyses (i.e. Period 1 vs Period 2 and Period 1 vs Period 3) were done on all derived variables. Only the Period 1 vs Period 3 analyses are presented, however, the Period 1 vs Period 2 analyses are referred to in the text where relevant. 
Within-location variability in the assemblages was determined by haphazardly photographing 10 replicate quadrats (photo-quadrat dimensions: $0.8 \mathrm{~m} \times$ $0.56 \mathrm{~m}$, total area $0.45 \mathrm{~m}^{2}$ ) at each of 3 sites nested within each location. At each location, the 3 sites (approximately $50 \mathrm{~m}$ in diameter and $50 \mathrm{~m}$ apart) were randomly selected each time.

Analysis of photographs and taxonomic discrimination. The photo-quadrats were analysed using a Bell and Howell 'black box' projector. An overlay plastic grid of 100 regularly spaced points was placed on the screen and estimates of the percentage cover and number of species were recorded from the photoquadrat (Roberts et al. 1994).

To help differentiate the taxa recorded in quantitative photo-quadrats, invertebrate collections were made at all locations. An in situ, close-up $35 \mathrm{~mm}$ colour photograph was taken of each specimen prior to collection as a permanent record of the habit of the organism. Many invertebrates (especially sponges) lose colour and shape once out of the water so another photograph was taken on the surface and the samples were labelled and immediately frozen for later identification. This voucher collection was lodged with the Queensland Museum, Australia.

Univariate statistical analyses. Since there was only one outfall location, asymmetrical analyses of variance were used to examine the differences between the outfall and the 2 control locations (Underwood 1992, 1993). Asymmetrical, before/after-control/impact (Beyond $\mathrm{BACI}$ ) designs, their mechanics and their potential for detecting both temporal and spatial disturbances have been discussed in detail by Underwood (1991, 1992, 1993, 1994). An example of the model used here is shown in Table 1, whilst the logic associated with interpreting these types of analyses are fully discussed by Underwood (1993, 1994). In this case, there were 2 fixed periods, with 4 random times within each period. The outfall versus controls (OvsC) term was considered fixed, whilst the term between controls was random. Sites were randomly nested within locations. The asymmetrical analyses repartition a fully orthogonal model, which thus allows a priori comparisons between the outfall and the average of the controls (Underwood 1992). The data associated with both the outfall and controls were analysed using a fully orthogonal design in which sites were nested within locations and time was considered a random factor within periods. A second analysis was then done on only those data associated with the controls. The asymmetrical component, or outfall versus control partition, was calculated by subtracting the sums of squares of the second analysis from those of the first. What was left was the variance associated with the potentially impacted outfall location. The various factors within the analysis were calculated using the same logic, as were the partitioned interactions associated with the various main effects (see Underwood 1993). Appropriate F-tests were constructed (see Table 1) using the principles outlined in Underwood (1981).

As Underwood (1981) notes, significant higher order interactions, e.g. Time(Period) $\times$ Sites(Location), mean that lower order interactions and main effects generally cannot be interpreted and should not be reported. Where significant Time(Period) $\times$ Sites(Location) interactions occurred, a 2 -tailed $F$-test was used to compare the temporal variability among sites within control locations with the temporal variability among sites at the outfall (Underwood 1992). This allowed a direct comparison of the effects of the outfall at these smaller spatial scales. Post hoc pooling procedures were used when the Time(Period) $\times$ Sites(Location) or Time (Period) $\times$ Location interactions were found to be nonsignificant at $\mathrm{p}=0.25$; this allowed appropriate $F$-tests to be constructed for lower order interactions and main effects (Winer 1971). Furthermore, where significant differences occurred in the Time(Period) $\times$ Sites(Location) and the Time(Period) $\times$ Location interactions (and their partitions), the Period $\times$ OvsC interaction was reported so that the trend above these higher order interactions could be examined (Underwood et al. 1993). It should be noted that this is not generally done because the significant higher order interactions warn that the lower order interactions are not independent (Underwood 1981). It should also be noted that when many repeated significance tests are done there is always a danger of increasing the probability of making Type I errors (Clarke \& Warwick 1994)

Prior to analysis, the data were examined for homogeneity of variances using Cochran's test (Winer 1971). Where variances were heterogeneous, data were transformed to $\log (x+0.5)$ for number of taxa and transformed to arc sine for percentage cover (Winer 1971). Where transformations did not result in homogeneous variances, analyses were done on the untransformed data (Underwood 1981). If variances could not be stabilized at $\mathrm{p}=0.05$ but could be stabilized at $p=0.01$, the analysis of variance was done using the $\mathrm{p}=0.01$ probability level (Underwood 1981). Where significant differences were found in the analysis of variance, Student-Newman-Keuls (SNK) multiple comparisons were done at the appropriate alpha level to determine differences among means (Winer 1971).

Multivariate statistical analyses. Multivariate statistical techniques were used to analyse the variation in species abundance and composition at each location and at each time using the PRIMER software package (Plymouth Marine Laboratories, UK). Abundance data for each location and time $(n=30)$ were doublesquare-root transformed to reduce weighting given to 
(a) Fauna

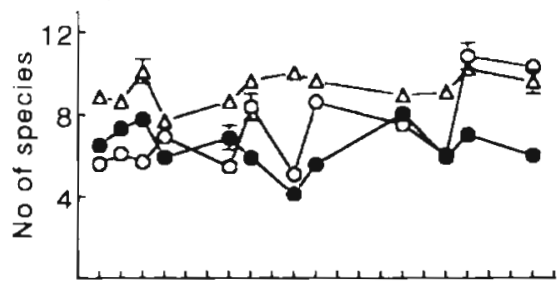

(d) Sponges

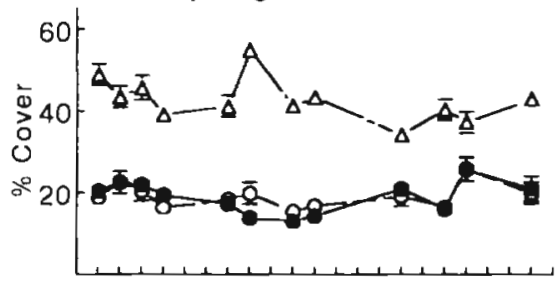

(g) Goodinal/a

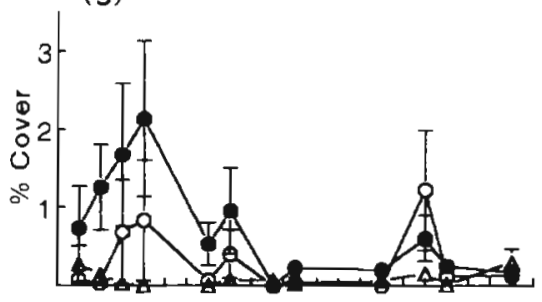

(j) Foliose algae

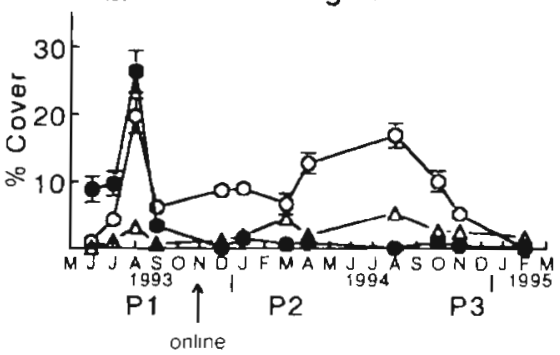

(b) Fauna

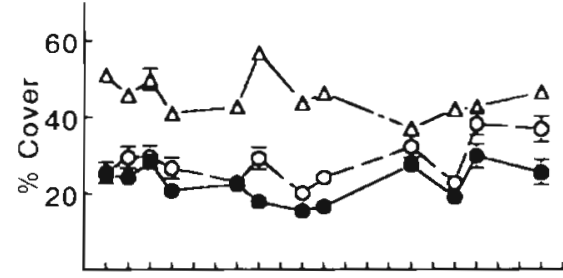

(e) Cymbastela concentrica

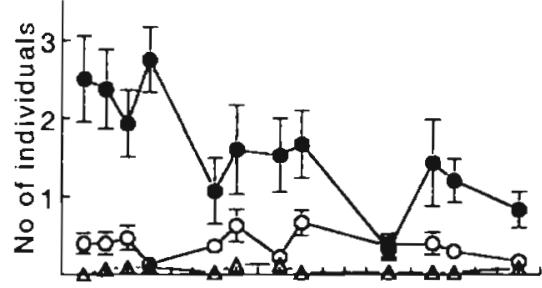

(h) Spongia

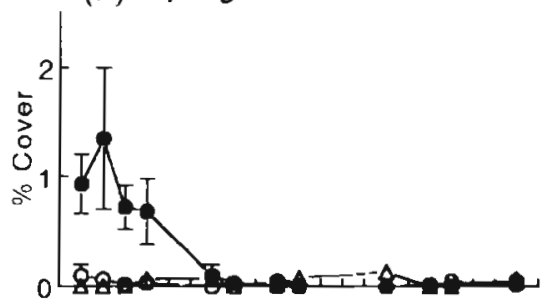

(k) Crustose algae

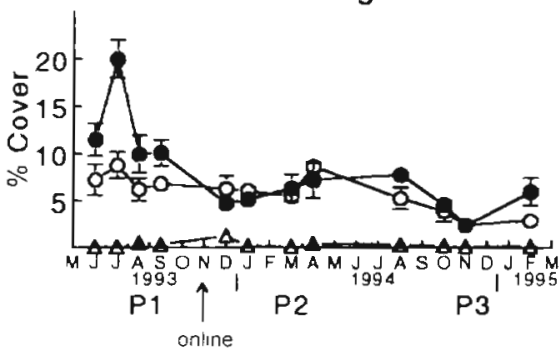

(c) Sponges

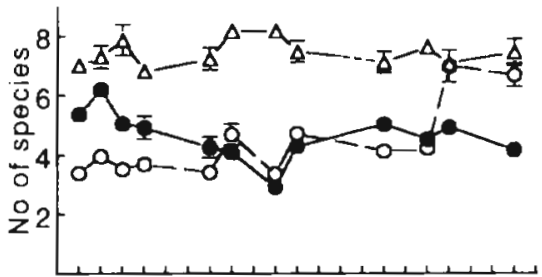

(f) Cymbastola concentrica

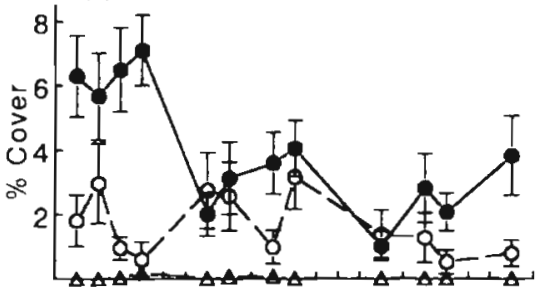

(i) Algae

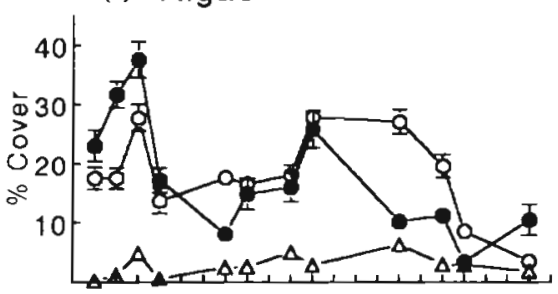

(I) Silt matrix

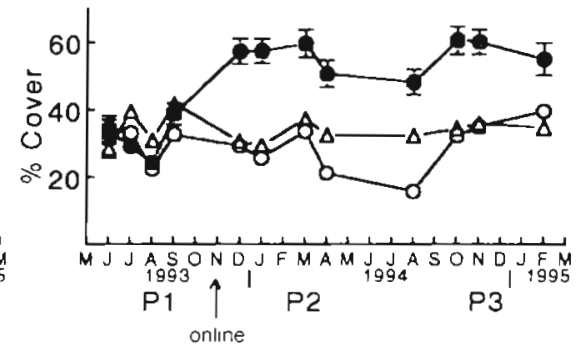

Fig. 2. Mean number of species or individuals and \% cover ( \pm SE) for selected taxa analysed from ( $\bullet$ ) Boulder Bay, (o) Point Stephens, and $(\Delta)$ Tomaree Head $(n=30)$. Online: sewage discharge began

abundant taxa and increase the weighting given to rarer taxa. The Bray-Curtis similarity matrix was used to generate 2-dimensional plots with the non-metric multi-dimensional scaling (nMDS) technique (Clarke 1993). Two-way analysis of similarity (ANOSIM) tests were used to examine the differences between periods and locations, while the similarity percentages (SIMPER) procedure was used to identify the major species contributing to the similarity measure obtained (Clarke \& Warwick 1994).

\section{RESULTS}

Sponges were the most species-rich and abundant taxon encountered at all locations; over 100 species were identified, including erect and encrusting forms. Of the 3 other major phyla, we recorded 37 ascidian species, 17 bryozoan species and 17 species of cnidarian. Many of the species of sponges encountered are listed in Appendix 1 of Roberts \& Davis (1996). A complete list of the species is available from the authors on 
A

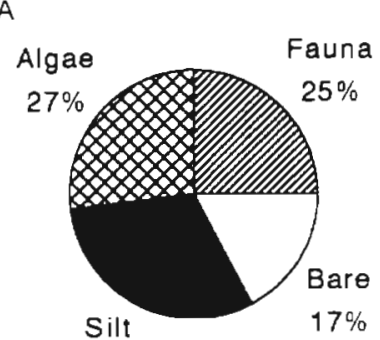

$31 \%$

B

Fig. 3. Mean cover estimates of the 4 major components of the subtidal encrusting assemblage (total fauna and algae, silt matrix and bare space) at $(A)$ the outfall and $(B)$ the average of the controls (Period 1: before sewage discharge, Periods 2 and 3: after sewage discharge)

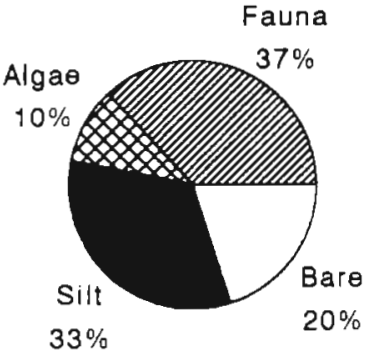

Period 1

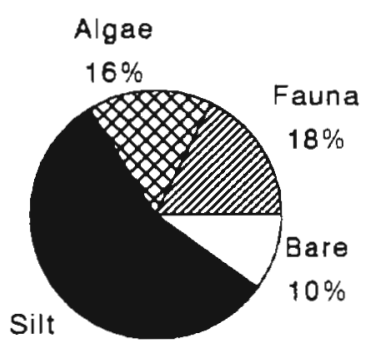

$56 \%$

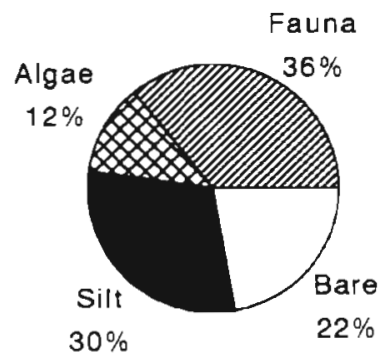

Period 2

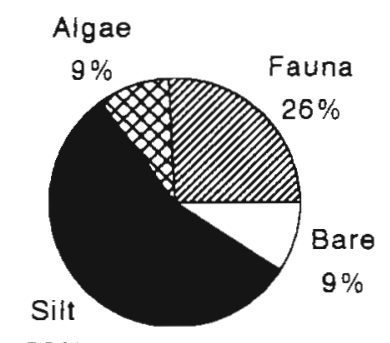

$56 \%$

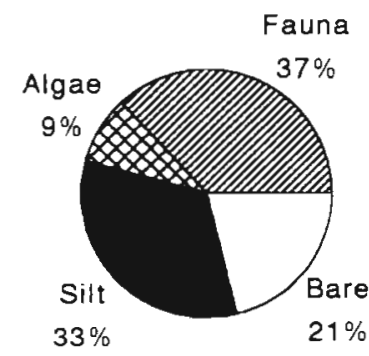

Period 3

request. The most abundant algae were crustose Corallinacea from the Order Cryptonemiales and a mixture of macroscopic foliose species. Since the algae were not readily identifiable from the photographs, they were grouped as foliose or crustose taxa.

\section{Changes in cover and richness}

The richness and cover of many of the taxa observed in this study fluctuated at various spatial and temporal scales. As judged by their response to the outfall, taxa may be split into 3 groups: (1) those for which no significant change in cover or richness occurred, (2) those that showed a decrease, and (3) those that showed an increase. For the sake of brevity, only selections of the taxa are presented here. The means and standard errors presented (Fig. 2) were calculated after the 3 sites within each location were pooled, i.e. $\mathrm{n}=30$. This makes the values for locations at each time look far more precisely determined than they actually were. Significant differences among sites were found and ideally all sites should have been plotted. We have not done this because the sites were randomly nested within each location and therefore plotting a time course for each of the random sites would be pointless and generally makes the figures uninterpretable.

\section{Taxa which showed little change at the outfall}

Following the commissioning of the outfall, no significant differences were detected in the richness or cover

for total fauna or sponges (Fig. 2a-d, Table 1a). Significant differences in richness were detected in the Time (Period) $\times$ Sites(Location) interaction; however, this variation was primarily associated with differences among control sites (Table 1a). Whilst the cover of the total fauna appeared to decrease after the discharge of sewage (see Fig. 3), by Period 3 it had recovered to similar levels found in Period 1. Although not statistically significant, this reduction could represent a press disturbance to $30 \%$ of the original cover. Sponges were the major faunal contributors of both richness and cover in the assemblage, and their spatial and temporal patterns are therefore very similar to the total fauna (Fig. 2a-d). The location at Tomaree Head had the greatest richness and cover of sponges (Fig. 2c, d) perhaps as a result of being closer to and under the influence of stronger tidal currents from the estuary at Port Stephens (Fig. 1).

Taxa which decreased at the outfall

The abundance of several species of sponge decreased significantly in response to the commissioning of the outfall (Table $1 \mathrm{a}, \mathrm{b}$ ). The number of individuals of the sponge Cymbastela concentrica (Lendenfeld) was significantly reduced by approximately one third (Fig. 2e, Table 2) after the outfall came online. By Period 3, they had been further reduced by another third (Fig. 2e, Tables 1a \& 2). A significant Time $($ Period $) \times($ OvsC) interaction was also detected (Fig. 2e, Table 1a) because of a reduced number of individuals recorded in the August 1994 


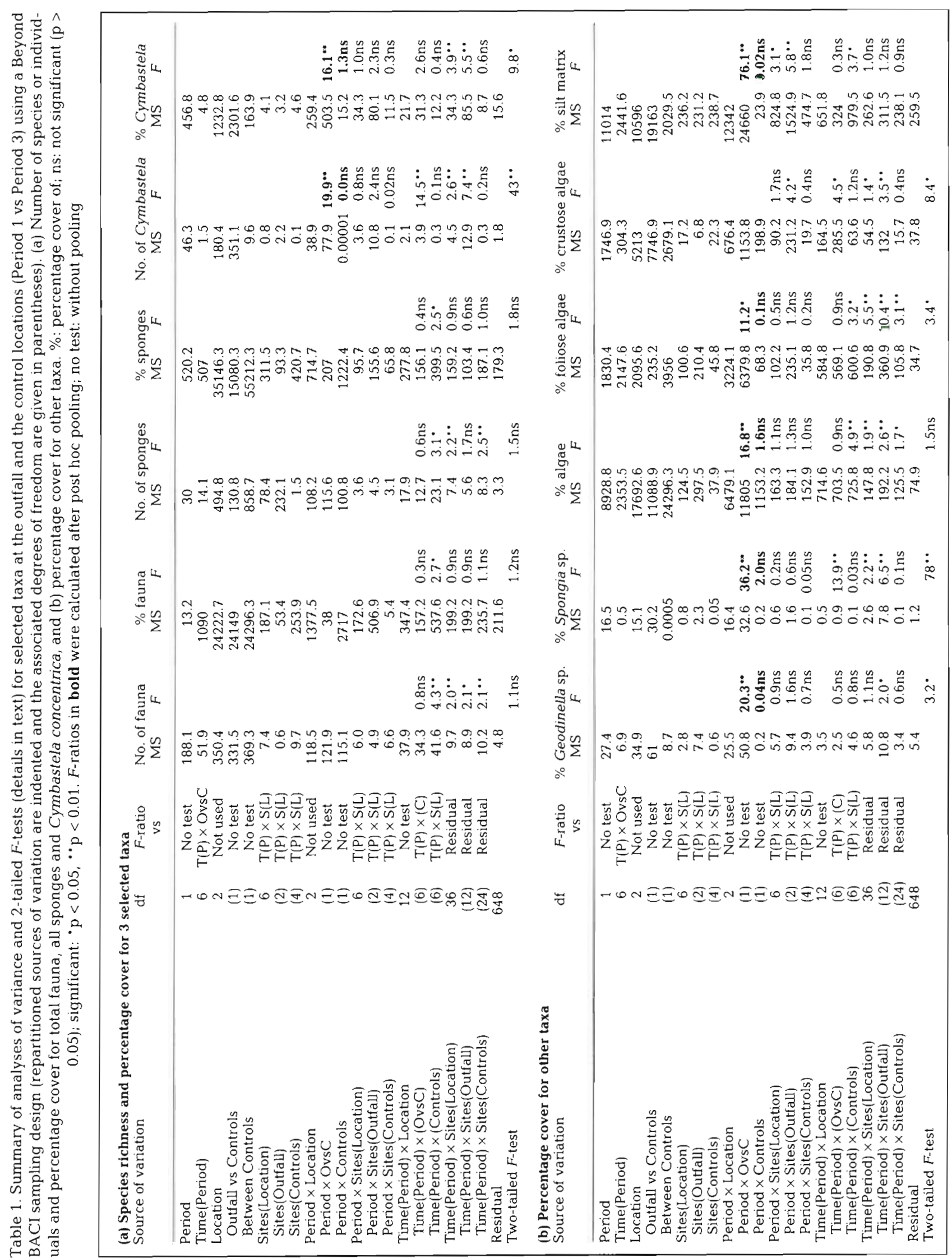


Table 2. Summary of SNK tests on the means [number of individuals (\#) and percentage cover of each taxa] of each of the 3 periods [Period 1 (P1): before sewage discharge; Period 2 (P2): immediately after; Period 3 (P3): approximately 1 yr after] at each of the 3 locations (Boulder Bay: outfall; Point Stephens and Tomaree Head: controls). =: Means not significantly different at $p=0.05$

\begin{tabular}{|c|c|c|c|}
\hline Taxa & Boulder Bay & Point Stephens & Tomaree Head \\
\hline Cymbastela concentrica (\#) & $\mathrm{P} 1>\mathrm{P} 2>\mathrm{P} 3$ & $\mathrm{P} 1=\mathrm{P} 2=\mathrm{P} 3$ & $\mathrm{P} 1=\mathrm{P} 2=\mathrm{P} 3$ \\
\hline Cymbastela concentrica & $\mathrm{P} 1>\mathrm{P} 2=\mathrm{P} 3$ & $\mathrm{P} 1=\mathrm{P} 2=\mathrm{P} 3$ & $\mathrm{P} 1=\mathrm{P} 2=\mathrm{P} 3$ \\
\hline Geodinella sp. & $\mathrm{P}_{1}>\mathrm{P}_{2}=\mathrm{P}_{3}$ & $\mathrm{P} 1=\mathrm{P} 2=\mathrm{P} 3$ & $\mathrm{P} 1=\mathrm{P} 2=\mathrm{P} 3$ \\
\hline Spongia sp. & $\mathrm{P} 1>\mathrm{P} 2=\mathrm{P} 3$ & $\mathrm{P} 1=\mathrm{P} 2=\mathrm{P} 3$ & $\mathrm{P} 1=\mathrm{P} 2=\mathrm{P} 3$ \\
\hline Total algae & $\mathrm{P} 1>\mathrm{P} 2=\mathrm{P} 3$ & $\mathrm{P} 1=\mathrm{P} 2=\mathrm{P} 3$ & $\mathrm{P} 1=\mathrm{P} 2=\mathrm{P} 3$ \\
\hline Foliose algae & $\mathrm{P} 1>\mathrm{P} 2=\mathrm{P} 3$ & $\mathrm{P} 1=\mathrm{P} 2=\mathrm{P} 3$ & $\mathrm{P} 1=\mathrm{P} 2=\mathrm{P} 3$ \\
\hline Crustose algae & $\mathrm{P} 1>\mathrm{P} 2=\mathrm{P} 3$ & $\mathrm{P} 1=\mathrm{P} 2=\mathrm{P} 3$ & $\mathrm{P} 1=\mathrm{P} 2=\mathrm{P} 3$ \\
\hline Silt matrix & $\mathrm{P} 1<\mathrm{P} 2=\mathrm{P} 3$ & $\mathrm{P} 1=\mathrm{P} 2=\mathrm{P} 3$ & $\mathrm{P} 1=\mathrm{P} 2=\mathrm{P} 3$ \\
\hline
\end{tabular}

(Period 3) sampling. The cover of C. concentrica also declined significantly $(\sim 50 \%)$ once the outfall was commissioned (Fig. 2f, Tables 1a \& 2); however, no differences were detected between Periods 2 and 3 using the SNK procedure (Table 2). Significant smallscale spatial and temporal variation occurred for both the number and cover of $C$. concentrica and 2-tailed $F$-tests indicated that this variation was associated with the outfall (Table 1a). In general, no significant fluctuations in the number or cover of this species occurred at either of the control locations (Fig. 2e, f, Tables 1a \& 2).

The sponges Geodinella sp. (Fig. 2g) and Spongia sp. (Fig. 2h) almost disappeared completely from the outfall location after the discharge of sewage began (Table 1b). No such changes occurred in the cover or number of these 2 species at the control locations (Fig. 2g, h, Table 2). Furthermore, the 2-tailed F-tests confirmed that the significant higher order interactions were due to greater variation associated with the outfall sites through time (Table 1b).

At all locations the richness of algae was low, with most of the cover attributable to foliose and crustose corallines. Generally, the cover of algae was greater at the outfall and the Point Stephens control compared to Tomaree Head (Fig. 2i). The total cover of algae fluctuated significantly at the outfall and control locations through time (Fig. 2i, Table 1b). However, the mean cover of algae at the outfall location in Periods 2 and 3 was significantly lower than the mean cover in Period 1 (Tables 1 b \& 2, refer to Fig. 3). No significant differences between periods were found in the cover of algae at the control locations (Table 2). Although the cover of algae fluctuated significantly within periods, the overall mean was generally reduced after the discharge of sewage (Fig. 3).

The cover of foliose algae at the outfall was almost reduced to zero by the end of the study (Fig. 2j). It was detected as a significant Period $\times$ OvsC interaction (Table $1 \mathrm{~b}$ ), with Period 1 having significantly greater cover than either of Periods 2 or 3 (Table 2). The cover of foliose algae declined at all locations following the August 1993 sampling, i.e. prior to sewage discharge (Fig. 2j); however, the overall mean trajectories at the control locations did not show a general decrease and there were no significant differences between periods (Table 2).

The cover of crustose coralline algae was significantly reduced after the discharge of sewage at the outfall (Fig. 2k, Table 1b). There were no significant differences between periods in the mean cover of crustose algae at the controls (Table 2). A significant Time (Period) $\times($ OvsC) interaction occurred at the outfall because of an increase in the cover of crustose algae in July 1993, i.e. prior to sewage discharge (Fig. 2k, Table 1b). A 2-tailed F-test found that a significant Time(Period) $\times$ Sites(Location) interaction was associated with increased variability at the outfall location (Table 1b).

\section{Taxa which increased at the outfall}

The percentage cover of the silt matrix was found to increase significantly at the outfall location following the discharge of sewage (Figs. 21 \& 3, Table 1b). This matrix consisted of a non-specific mixture of microflora and -fauna, silt and microorganisms and has been described previously (Roberts et al. 1994). The silt matrix increased rapidly and dramatically from an average cover of around $35 \%$ at the outfall and control locations, to around $55 \%$ at the outfall location following its commissioning (Fig. 2l, Table 2). A significant Time(Period) $\times$ (Controls) interaction (Table 1 b) was due to a reduction in silt matrix at the Point Stephens control location (Fig. 2l) in April (Period 2) and August 1994 (Period 3). A proportion of bare space at the outfall location appeared to be covered by the silt matrix during Periods 2 and 3 (Fig. 3). 
Table 3. Summary of 2-way analysis of similarities (ANOSIM) comparing differences in the structure of the assemblages at each location and period. The first period (P1) was in the pre-commissioning phase whilst P2 and P3 were postcommissioning periods. BB: Boulder Bay; PS: Point Stephens; TH: Tomaree Head; ns: not significant $(p>0.05)_{i}{ }^{*}$ significant $(p<0.05)$

\begin{tabular}{llclllll|}
\hline Location & $R$ & BB & $R$ & PS & $R$ & TH & $R$ \\
\hline BB vs PS & $0.93^{\circ}$ & P1 vs P2 & $0.53^{\circ}$ & P1 vs P2 & 0.19 ns & P1 vs P2 & $0.25 n s$ \\
PS vs TH & $1^{\circ}$ & P2 vs P3 & $0.64^{\circ}$ & P2 vs P3 & 0.24 ns & P2 vs P3 & $0.19 n s$ \\
TH vs BB & $1^{\circ}$ & P3 vs P1 & $0.71^{\circ}$ & P3 vs P1 & 0.54 ns & P3 vs P1 & $0.69^{\circ}$ \\
\hline
\end{tabular}

contrast, no significant differences were found between periods at the Point Stephens location, but Period 1 at Tomaree Head was significantly different from Period 3 (Table 3).

The SIMPER procedure ranked, in order of importance, those species that contributed most to the similarities within a location for a given time period. Although only the species ranked in the 'top ten' are included in Table 4 , it is clear that species of

\section{Changes in community structure}

The multivariate analyses clearly demonstrated that the assemblages at the 3 locations were significantly different from each other during the first sampling period and that rapid changes occurred to the assemblage at the outfall following the discharge of sewage. The ANOSIM detected significant differences among all 3 locations and all periods at the outfall (Table 3). In importance were usually quite different among locations but were, in general, more consistent among time periods within a location. In the first period at the outfall location, 6 sponges featured within the top ranked species, however, they did not rank at all in Periods 2 or 3 (Table 4). This indicated that their relative abundance at the outfall location had decreased or became less important in terms of representing community structure.

Table 4. Species ranked in order of importance (1 to 10 presented only) which contributed to the similarities within a location/ period as determined using SIMPER. B: Boulder Bay; P: Point Stephens; T: Tomaree Head 1 : Period 1; 2: Period 2; 3 : Period 3

\begin{tabular}{|c|c|c|c|c|c|c|c|c|c|c|}
\hline Taxon & Species & B1 & $\mathrm{B} 2$ & B3 & P1 & P2 & P3 & T1 & $\mathrm{T} 2$ & T3 \\
\hline \multirow[t]{27}{*}{ Porifera } & Cymbastela concentrica & 1 & 2 & 2 & 4 & 2 & 10 & & & \\
\hline & Spirastrella sp. & 3 & 1 & 1 & 1 & 1 & 1 & & 10 & \\
\hline & Ceratopsion aurantiaca & & 8 & & & & & & & \\
\hline & Xytopsene sp. & 6 & & & & & & & & \\
\hline & Spongia sp. & 7 & & & & & & & & \\
\hline & Cliona (Raphyrus) hixonii & & & & & & & 10 & 7 & \\
\hline & Tedania sp. & 4 & 3 & 9 & 3 & 6 & 8 & & 8 & 6 \\
\hline & Ircinia sp. & 10 & & 3 & 10 & 9 & 6 & & & \\
\hline & Tedania digitata & & & & & & & & & 8 \\
\hline & Cribrochalina sp. 1 & & & & & & & 3 & 4 & 7 \\
\hline & Stylinos sp. & & & & & & & 8 & & \\
\hline & Thorecta sp. & 9 & & & & & & & & \\
\hline & Acarnus sp. & & & & & & & 6 & 2 & 2 \\
\hline & Phoriospongia sp. & & & & & & & & & 5 \\
\hline & Clathria (Dendrocia) pyramida & 8 & & & & & & & & \\
\hline & Callyspongia sp. & & & & 8 & 4 & 4 & 9 & & \\
\hline & Mycale (Arenochalina) flammula & & & & & & & 2 & 1 & 1 \\
\hline & Mycale (Aegogropila) sp. & & & & & & & 7 & & \\
\hline & Hymedesmia sp. & 5 & 7 & 4 & 9 & & & & & \\
\hline & Phoriospongia sp. & & & & & & 5 & & & \\
\hline & Geodinella sp. & 2 & & & & & & & & \\
\hline & Antho (Isopenectya) chartacea & & & & 5 & 7 & 9 & & & \\
\hline & Crella incrustans & & 10 & & & & & 4 & 3 & 3 \\
\hline & Desmapsamma kirki & & & & & & & & 6 & 4 \\
\hline & Dendrilla sp. & & & 6 & 7 & 8 & 7 & 5 & 5 & 10 \\
\hline & Psammocinia sp. & & 4 & 5 & & & & & & \\
\hline & Cribrochalina sp. 2 & & & & & & & 1 & 9 & \\
\hline Bryozoa & Steginoporella truncata & & & & 6 & 5 & 2 & & & \\
\hline \multirow[t]{4}{*}{ Ascidaceae } & Didemnum sp. & & 9 & 10 & & & & & & \\
\hline & Cnemidocarpa pedata & & 6 & 8 & & 10 & & & & \\
\hline & Lissoclinum sp. & & & & & & & & & 9 \\
\hline & Pyura spinifera & & 5 & 7 & 2 & 3 & 3 & & & \\
\hline
\end{tabular}


Changes were also apparent in the relative importance of ascidians at the outfall location during Periods 2 and 3. During Period 1 at the outfall, no ascidians were ranked within the top 10 (Table 4). However, by Periods 2 and 3 one colonial, Didemnum sp., and 2 solitary ascidians, Pyura spinifera (Quoy \& Gaimard) and Cnemidocarpa pedata (Herdman), had increased their relative importance as contributors to the similarities at the outfall (Table 4). It should be noted that this increase in the importance of ascidians is due to a decrease in the importance of sponges.

The dramatic and rapid changes to the structure of the benthic assemblages at the outfall location are clearly portrayed in the nMDS ordination (Fig. 4). The 2-dimensional plot reveals clear separation among all locations, yet considerable overlap is apparent for points from all time periods at the control locations. In contrast, at the outfall location the data points representing pre-commissioning (Period 1) are clearly separated from the post-commissioning points (Periods 2 and 3). There is also a degree of separation between the second and third periods (Fig. 4). Stress for this ordination was considered to be good (Stress $=0.11$ ) with no real risk of drawing false inferences (Clarke 1993).

\section{DISCUSSION}

Here we report rapid changes to sessile macrobenthic assemblages following the commissioning of an ocean outfall at Boulder Bay, New South Wales, Australia. Within 3 mo of the release of sewage effluent into the environment the effects on the community were far reaching, with statistically significant reductions in the abundance of encrusting invertebrates and algae. A number of species of sponge almost disappeared completely from the outfall location. Moreover, the SIMPER analysis indicated that the community in the vicinity of the outfall changed from one dominated by sponges to one in which ascidians became an important component of the fauna.

Drastic reductions in species richness and increases in the abundance of a small number of tolerant species have been recorded previously in the vicinity of ocean outfalls (May 1985, Fairweather 1990, Lopez Gappa et al. 1990). However, the majority of studies have not had the opportunity to compare pre- and post-impact data and hence are likely to have missed many of the subtle short-term changes we report here. Our study also benefited from a combination of multivariate and univariate analyses to examine changes in the structure of the encrusting assemblages. The effects of ocean outfalls on biological assemblages have been described using multivariate (Clarke 1993, Smith \& Simpson 1993) or univariate techniques (Otway et al.

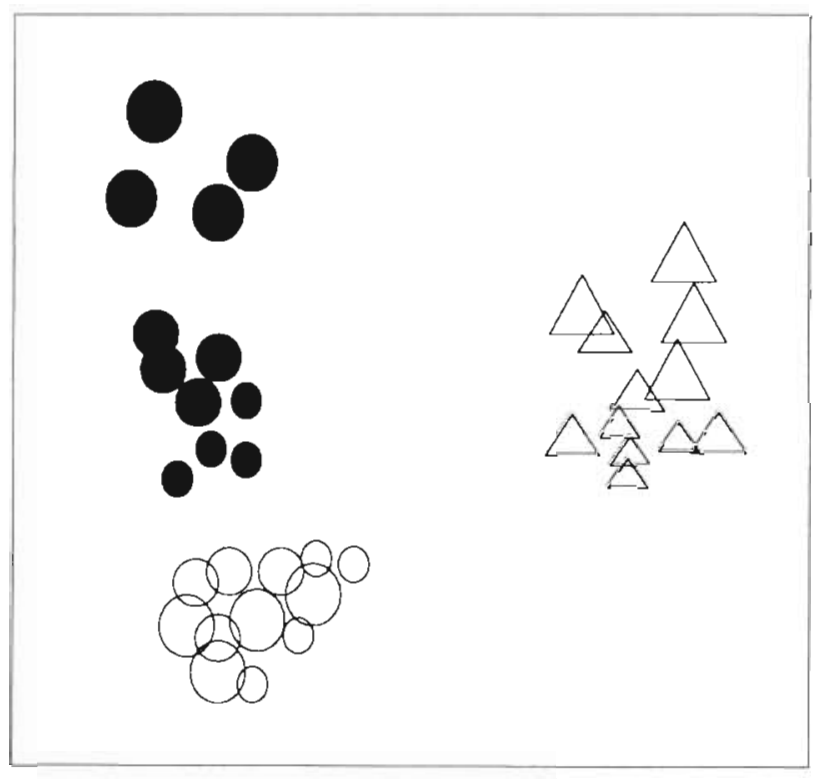

Fig. 4. Non-metric multidimensional scaling (nMDS) plots for the abundance of species at each location and time (data points are averages for the 3 sites at each time Boulder Bay (outfall): (O) Period 1, (๑) Period 2, (•) Period 3; Point Stephens (control): (O) Period 1, (O) Period 2, (0) Period 3; Tomaree Head (control): $(\Delta)$ Period 1, $(\Delta)$ Period 2, $(\Delta)$ Period 3

1996a); however, the use of a combination of these techniques is rare (but see Chapman et al. 1995, Otway et al. 1996b). Underwood \& Peterson (1988) and Warwick (1993) emphasise the need to use all available techniques of analysis, as different approaches examine different components of the assemblage and are therefore more likely to detect effects.

The importance of appropriate temporal scales to measure variation in these dynamic communities cannot be overlooked and may be more important than examining smaller scale spatial patterns. In this study many higher order, small-scale temporal and spatial interactions occurred. These interactions warn us that main effects and lower order interactions may be unreliable and are not independent (Underwood 1981). Small-scale, within-site variation was found for most taxa in this study, and understanding the mechanisms leading to this variability would greatly assist in identifying the effects of anthropogenic disturbance. The contrasts we made here between small-scale spatial and temporal variability at the outfall and the controls demonstrated that the outfall did affect within-site variability in the cover and number of a range of taxa. This is important because it indicates that sewage discharged into these habitats can effect them on very small spatial scales. Warwick \& Clarke (1993) examined various assemblages and concluded that increased variability among samples may be a general feature exhibited by assemblages under stress. 
In reporting changes in pattern associated with the commissioning of an ocean outfall it is instructive to consider the potential mechanisms which may be operating A discharge of primary or secondary treated sewage has the potential to increase nutrients and suspended solids (silt) and decrease the salinity in the vicinity of the discharge. There is evidence that ocean outfalls increase the level of suspended solids in the water column at or near the point of the discharge (Coade 1995) and may reduce the amount of photosynthetic active radiation at the bottom (Kirk 1983).

The direct effects of sedimentation on the structure and dynamics of encrusting communities have rarely been reported, but it is clear that some species of sponge are sensitive to burial beneath sediment (Wulff 1997). Moreover, reductions in the pumping rate of sponges may occur when the concentration of sediment increases (Gerodette \& Flechsig 1979). There is also correlative evidence that the structure of encrusting communities change along sedimentation gradients (Carballo et al. 1996, Naranjo et al. 1996). Field and flume studies of the morphology of some invertebrates indicate sensitivity to high rates of sedimentation (Riegl et al. 1996). Some members of the benthic assemblage we examined share this morphology, e.g. Cymbastela concentrica, and may be vulnerable to increased sedimentation.

Sewage plumes often act to shade the bottom, and this reduction in light may limit the growth of benthic algae (Vadas \& Steneck 1988). These effects may not be restricted to algae however. Many invertebrates, including Cymbastela concentrica, play host to symbiotic micro-algae, which can account for a major part of their nutritional requirements (Wilkinson 1983, Cheshire et al. 1995). Increased concentrations of nutrients within sewage can alter the growth rates of macroalgae (Borowitzka 1972), whilst low salinity can decrease the diversity and abundance of sponge-dominated assemblages (Storr 1976). Clearly, the processes producing change in the assemblages and at the species level at the outfall are likely to be complex and require detailed experimental examination.

Our data imply that the paradigm that encrusting assemblages from temperate reefs are relatively stable through time needs to be re-examined. It is acknowledged that episodic storm events can produce rapid change in these communities, particularly in shallow water (e.g. Kennelly 1987). In deeper or more sheltered habitats benthic assemblages have been considered to be relatively stable, although they may be highly dynamic at a small scale (Ayling 1983, Kay \& Butler 1983). More recently, Chapman et al. (1995) concluded that the decommissioning of a large shoreline sewage outfall produced no significant difference in an encrusting assemblage when compared to 2 control locations. They noted that their study began 3 mo after the flow of sewage ceased but believed that their interpretations were valid because of the slow changes experienced by these types of assemblages. In contrast, Roberts \& Davis (1996) described significant temporal fluctuations (within $4 \mathrm{mo}$ ) in shallow temperate reef sponge assemblages in both shallow and deep water off the East Coast of Australia. Davis et al. (1997) reported that sponge-dominated assemblages from similar habitat types at the mouth of an embayment responded quickly to biological disturbance.

Our study emphasises a persistent problem with assessing impacts on communities and that is the selection of appropriate reference or control sites. The structure of the assemblages at the 3 locations investigated in this study differed markedly from the outset. As Underwood (1992) notes, the control locations do not have to be identical but an important requirement is that they come from a population of apparently similar locations. We believe that in our study the locations were spatially independent, so that there was no spatial autocorrelation among locations confounding our ability to identify impacts of the outfall.

Here we recorded what might be termed a significant 'press perturbation' correlated with the commissioning of an outfall (see Glasby \& Underwood 1996 for a review of this topic). We believe that the changes at the outfall can be attributed to the release of sewage, as no such changes were observed at the control locations. In addition, the rapid increase in the cover of the silt matrix suggests that the outfall is the causative agent. However, in the absence of direct experimental evidence, namely, changes in the survivorship of sensitive species following their reciprocal transplantation to an outfall location and replicated reference locations, it is not possible to infer causality. These manipulative experiments will be the focus of future work on the processes occurring in encrusting marine assemblages exposed to sewage.

Acknowledgements. We thank Sharon Cummins for field assistance Ted Roberts for the use of the facilities at the Port Stephens Research Station (NSW Fisheries); Dr John Hooper for identifying the sponge fauna and comments on the $\mathrm{ms}$; Dr Tony Roach for his advice with the experimental design and statistical analyses; Jan Roberts for data entry and editing; Drs David Leece, Tony Church, Ross Higginson, Peter Scanes and Klaus Koop for logistic and management support; 3 anonymous reviewers for improving the manuscript. We are indebted to Professor Tony Underwood for his patience and advice with the statistical analyses and the experimental design. The Environment Protection Authority provided logistic support for the study, which represents contribution No. 173 from the Ecology \& Genetics Group, University of Wollongong 


\section{LITERATURE CITED}

Ayling AL (1983) Growth and regeneration rates in thinly encrusting demospongae from temperate waters. Biol Bull (Woods Hole) 165:343-352

Borowitzka MA (1972) Intertidal algal species diversity and the effect of pollution. Aust J Mar Freshwat Res 23:73-84

Butler AJ, Connolly RM (1996) Development and long term dynamics of a fouling assemblage of sessile marine invertebrates. Biofouling 9:187-209

Carballo JL, Naranjo SA, Garcia-Gomez JC (1996) The use of sponges as stress indicators in marine ecosystems at Algeciras Bay (southern Iberian Peninsular). Mar Ecol Prog Ser 135:109-122

Chapman MG, Underwood AJ, Skilleter GA (1995) Variability at different spatial scales between a subtidal assemblage exposed to the discharge of sewage and two control assemblages. J Exp Mar Biol Ecol 189:103-122

Cheshire AC, Butler AJ, Westphalen G, Rowland B, Stevenson J, Wilkinson CR (1995) Preliminary study of the distribution and photophysiology of the temperate phototrophic sponge Cymbastela sp. from South Australia. Mar Freshwat Res 46:1211-1216

Clarke KR (1993) Non-parametric multivariate analysis of changes in community structure. Aust J Ecol 18:117-143

Clarke KR, Green RH (1988) Statistical design and analysis for a 'biological effects' study. Mar Ecol Prog Ser 46:213-226

Clarke KR, Warwick RM (1994) Change in marine communities: an approach to statistical analysis and interpretation. Natural Environment Research Council, Plymouth

Coade G (1995) Ocean water quality. Sydney Deepwater Outfalls Environmental Monitoring Program Final Report Series, Vol 3-water quality. NSW Environment Protection Authority, Sydney

Davis AR, Roberts DE, Cummins SP (1997) Rapid invasion of a sponge-dominated deep-reef by Caulerpa scalpelliformis (Chlorophyta) in Botany Bay, New South Wales. Aust J Ecol 22:146-150

Fairweather PJ (1990) Sewage and the biota on seashores: assessment of impact in relation to natural variability. Environ Monit Assess 14:197-210

Gerrodette T, Flechsig AO (1979) Sediment-induced reduction in the pumping rate of the tropical sponge Verongia lacunosa. Mar Biol 55:103-110

Glasby TM, Underwood AJ (1996) Sampling to differentiate between pulse and press perturbations. Environ Monit Assess 42:241-252

Green RH (1979) Sampling design and statistical methods for environmental biologists. John Wiley and Sons, New York

Kay AM, Butler AJ (1983) 'Stability' of the fouling communities on pier pilings of two piers in South Australia. Oecologia 56:70-78

Kennelly SJ (1987) Physical disturbance in an Australian kelp community. I. Temporal effects. Mar Ecol Prog Ser 40: 145-153

Kennelly SJ, Underwood AJ (1992) Fluctuations in the distribution and abundance of species in a sublittoral kelp forest in New South Wales. Aust J Ecol 17:367-382

Kirk JT (1983) Light and photosynthesis in aquatic ecosystems. Cambridge University Press, London

Lee R, Wallace S (1993) Hydrographic investigations for the Boulder Bay extended outfall. Technical Report 93/75, NSW Environment Protection Authority, Sydney

Littler MM, Murray SN (1975) Impact of sewage on the distribution, abundance and community structure of rocky intertidal macro-organisms. Mar Biol 30:277-291

Lopez Gappa JJ, Tablado A, Magaldi NH (1990) Influence of sewage pollution on a rocky intertidal community dominated by the mytilid Brachidontes rodriguezi. Mar Ecol Prog Ser 63:163-175

May V (1985) Observations on algal floras close to two sewage outlets. Cunninghamia 1:385-394

Muricy G (1991) Structure of sponge communities around the sewage outfall at Cortiou (Marseille, France). Vie Milieu 41:205-221

Naranjo SA, Carballo JL, Garcia-Gomez JC (1996) Effects of environmental stress on ascidian populations in Algeciras Bay (southern Spain). Possible marine bioindicators? Mar Ecol Prog Ser 144:119-131

Otway NM, Gray CA, Craig JR, McVea TA, Ling JE (1996a) Assessing the impacts of deepwater sewage outfalls on spatially- and temporally-variable marine communities. Mar Environ Res 41:45-71

Otway NM, Sullings DJ, Lenehan NW (1996b) Trophicallybased assessment of the impacts of deepwater sewage disposal on a demersal fish community. Environ Biol Fishes $37: 107-120$

Riegl B, Heine C, Branch GM (1996) Function of funnel shaped coral growth in a high-sedimentation environment. Mar Ecol Prog Ser 145:87-93

Roberts DE (1996) Patterns in subtidal marine assemblages associated with a deep-water sewage outfall. Mar Freshwat Res $47: 1-9$

Roberts DE, Davis AR (1996) Patterns in sponge (Porifera) assemblages on temperate coastal reefs off Sydney, Australia. Mar Freshwat Res 47:897-906

Roberts DE, Fitzhenry SR, Kennelly SJ (1994) Quantifying subtidal macrobenthic assemblages on hard substrata using a jump camera method. J Exp Mar Biol Ecol 177:157-170

Smith SDA (1994) Impact of domestic sewage effluent versus natural background variability: an example from Jervis Bay, New South Wales. Aust J Mar Freshwat Res 45 $1045-1064$

Smith SDA, Simpson RD (1992) Monitoring the shallow sublittoral using the fauna of kelp (Ecklonia radiata) holdfasts. Mar Pollut Bull 24:46-52

Smith SDA, Simpson RD (1993) Effects of pollution on the holdfast macrofauna of the kelp Ecklonia radiata: discrimination at different taxonomic levels. Mar Ecol Prog Ser 96:199-208

Storr JF (1976) Ecological factors controlling sponge distribution in the Gulf of Mexico and the resulting distribution. In: Harrison FW, Cowden RR (eds) Aspects of sponge biology. Academic Press, New York

Underwood AJ (1981) Techniques of analysis of variance in experimental marine biology and ecology. Oceanogr Mar Biol Annu Rev 19:513-605

Underwood AJ (1991) Beyond BACI: experimental designs for detecting human environmental impacts on temporal variations in natural populations. Aust J Mar Freshwat Res 42 $569-587$

Underwood AJ (1992) Beyond BACI: the detection of environmental impacts on populations in the real, but variable, world. J Exp Mar Biol Ecol 161:145-178

Underwood AJ (1993) The mechanics of spatially replicated sampling programmes to detect environmental impacts in a variable world. Aust J Ecol 18:99-116

Underwood AJ (1994) On beyond BACI: sampling designs that might reliably detect environmental disturbances. Ecol Appl 4:3-15

Underwood AJ, Chapman MG, Howitt L, Skilleter GA (1993) North Head ocean outfall project. Institute of Marine Ecology, University of Sydney, Sydney

Underwood AJ, Kingsford MJ, Andrew NL (1991) Patterns in shallow subtidal marine assemblages along the coast of 
New South Wales. Aust J Ecol 6:231-49

Underwood AJ, Peterson CH (1988) Towards an ecological framework for investigating pollution. Mar Ecol Prog Ser $46: 227-234$

Vadas RL, Steneck RS (1988) Zonation of deep water benthic algae in the Gulf of Maine. J Phycol 24:338-346

Warwick RM (1993) Environmental impact studies on marine communities: pragmatical considerations. Aust $J$ Ecol 18 : $63-80$

Editorial responsibility: Tony Underwood (Contributing Editor), Sydney, Australia
Warwick RM, Clarke KR (1993) Increased variability as a symptom of stress in marine communities. J Exp Mar Biol Ecol 172:215-226

Wilkinson C (1983) Net primary productivity in coral reef sponges. Science 219:410-412

Winer BJ (1971) Statistical principles in experimental design McGraw-Hill, New York

Wulff JL (1997) Mutualisms among species of coral reef sponges. Ecology 78:146-159

Submitted: October 1, 1997; Accepted: December 23, 1997

Proofs received from author(s): February 19, 1998 